\title{
Mitral valve repair using robotic technology: Safe, effective, and durable
}

\author{
Rakesh M. Suri, MD, DPhil, ${ }^{\mathrm{a}}$ Joseph A. Dearani, MD, ${ }^{\mathrm{b}}$ Tomislav Mihaljevic, MD, ${ }^{\mathrm{a}}$ \\ W. Randolph Chitwood, Jr, MD, ${ }^{\mathrm{c}}$ Douglas A. Murphy, MD, ${ }^{\mathrm{d}}$ Alfredo Trento, MD, \\ Hoda Javadikasgari, MD, ${ }^{\mathrm{a}}$ Harold M. Burkhart, MD, ${ }^{\mathrm{f}}$ Wiley L. Nifong, MD, ${ }^{\mathrm{c}}$ Richard C. Daly, MD, ${ }^{\mathrm{b}}$ and \\ A. Marc Gillinov, MD
}

\footnotetext{
From the a Department of Thoracic and Cardiovascular Surgery, Heart and Vascular Institute, Cleveland Clinic, Cleveland, Ohio; ${ }^{b}$ Division of Cardiovascular Surgery, Mayo Clinic, Rochester, Minn; ${ }^{\mathrm{c}}$ Department of Cardiovascular Sciences, East Carolina Heart Institute, Brody School of Medicine, East Carolina University, Greenville, NC; ${ }^{\mathrm{d} D i v i s i o n}$ of Cardiothoracic Surgery, Emory University School of Medicine, Atlanta, Ga; ${ }^{\mathrm{e} C e d a r s-S i n a i ~ H e a r t ~ I n s t i t u t e, ~ L o s ~ A n g e l e s, ~ C a l i f ; ~ a n d ~}{ }^{\mathrm{f} U n i v e r s i t y ~ o f ~ O k l a h o m a ~ H e a l t h ~ S c i e n c e s ~ C e n t e r, ~ O k l a-~}$ homa City, Okla.

Disclosures: Authors have nothing to disclose with regard to commercial support.

Received for publication Jan 1, 2016; revisions received Feb 1, 2016; accepted for publication Feb 18, 2016; available ahead of print March 22, 2016.

Address for reprints: Rakesh M. Suri, MD, DPhil, Department of Thoracic and Cardiovascular Surgery, Heart and Vascular Institute, Cleveland Clinic, 9500 Euclid Ave, Cleveland, OH 44195 (E-mail: surir@ccf.org).

J Thorac Cardiovasc Surg 2016;151:1450-4

$0022-5223 / \$ 36.00$

Copyright $(\underset{2}{ } 2016$ by The American Association for Thoracic Surgery

http://dx.doi.org/10.1016/j.jtcvs.2016.02.030
}

Robot-assisted mitral valve (MV) repair was introduced in the late 1990 s with the goal of improving the technical precision of less-invasive surgical MV reconstruction. The broad advantages of robotic MV repair include an excellent 3-dimensional view of the valve pathology and better maneuverability of the endoscopic instruments (Figure 1). In this review, we sought to (1) delineate the timing and patient selection criteria for robotic MV repair, (2) review important technical criteria, and (3) describe the early postoperative and midterm outcome advantages of this technology.

\section{WHAT ARE THE CONTEMPORARY INDICATIONS FOR MITRAL VALVE REPAIR AND WHAT IS THE IDEAL TIMING OF THE OPERATION?}

Over the past decade, there has been significant progress in the understanding of the deleterious natural history of uncorrected severe degenerative mitral regurgitation (MR), which has led to an evolution in the type of patients who are referred for robotic MV repair. This has led to a growing body of data supporting the performance of early MV repair. The recent 2014 American College of Cardiology (ACC)/American Heart Association (AHA) Heart Valve Guidelines thus have moved to categorize patients with severe chronic degenerative MR into 5 stages: (A) minimal disease, (B) progressive disease, (C1) severe MR in asymptomatic patients with preserved left ventricular (LV) function (LV ejection fraction $>60 \%$ or LV end-systolic diameter $<40 \mathrm{~mm}$ ), (C2) severe asymptomatic MR in patients with early evidence of LV dysfunction (LV ejection fraction $<60 \%$ or LV end-systolic diameter $>40 \mathrm{~mm}$ ), and surgical correction for patients in stages D and C2 is (D) severe symptomatic MR in patients. ${ }^{1}$ Although prompt

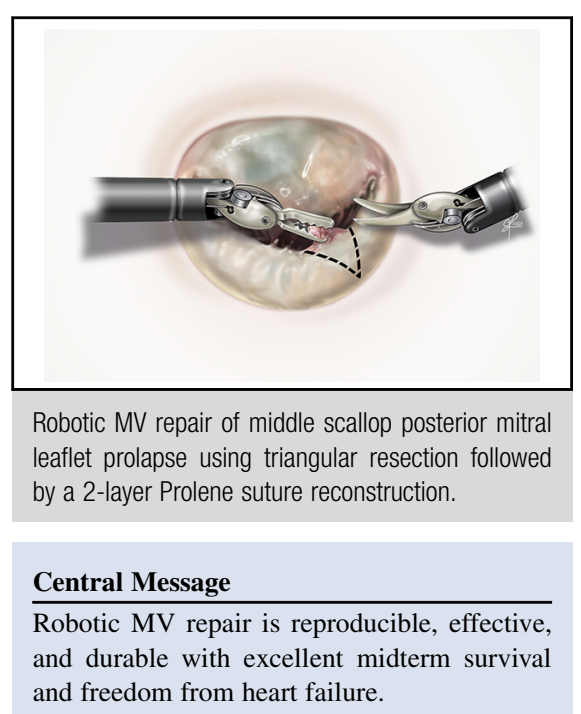

See Editorial Commentary page 1455 . strongly recommended (class I recommendation), there has been debate regarding the ideal timing of intervention for severe asymptomatic MR in patients without LV dysfunction (stage C1). Recently, new information supporting the advantages of prompt surgical correction of primary MR to both prevent excess long-term mortality and diminish heart failure risks $^{1,2}$ has led to a further evolution in thinking regarding the ideal timing for MV repair.

Evidence supporting the early referral of patients with severe asymptomatic MR with preserved $\mathrm{LV}$ function for MV repair can be divided into 4 main categories. First, severe uncorrected MR is a disease state with deleterious clinical outcomes, and MV surgery is unavoidable in this condition. ${ }^{3}$ Second, MV repair is now reproducible with approximately 99\% certainty; it is effective, durable, and safe with very low risks of postoperative mortality and morbidity, particularly in high-volume centers. $^{3-6}$ In contrast, percutaneous techniques, such as the MitraClip device (Abbott Vascular, Abbott Park, Ill), are reserved for highrisk inoperable patients merely requiring palliative downgrading, but not elimination of MR. ${ }^{7}$ Third, performance of MV surgery within 3 months of diagnosis results in significant improvements in long-term survival and freedom 
from heart failure. ${ }^{2}$ Finally, strategies capable of minimizing the perceived burden of early intervention, such as thoracoscopic port access approaches and robotic MV repair, are now routinely available at heart valve centers. These procedures can be cost-neutral in comparison with open operation at certain centers and are often associated with rapid patient recovery and quicker return to normal activity. ${ }^{3-6}$ Because delaying surgery until symptom onset during "watchful waiting" exposes patients to the risks of suboptimal outcomes and poor long-term survival, the class IIa recommendation to offer MV repair for asymptomatic patients without evidence of LV dysfunction when likelihood of repair is greater than $95 \%$ and risk is less than $1 \%$ has become more applicable in contemporary practice. ${ }^{1,8}$

The type and extent of MV disease also have historically affected the timing of referral for surgery because of the perception that patients with anterior leaflet prolapse are less ideal candidates for valve repair. Further, the 2014 ACC/AHA guidelines detail that although MR caused by posterior mitral leaflet prolapse (simple disease) often is reliably addressed by using both conventional and robotically associated approaches, recurrence of MR after repair of complex MV disease (severe multi-scallop degeneration or anterior leaflet involvement) traditionally has been assumed to be higher. ${ }^{1}$ In the past, this perception led to uncertainty about the ability of robotic approaches to effect durable correction of complex degenerative disease and thus tempered the widespread recommendation for early intervention in these patients. ${ }^{1}$ However, the recent demonstration that the midterm outcomes of robotic correction of primary MR are reproducibly excellent with equally impressive outcomes, high survival, excellent durability, and infrequent complications regardless of disease complexity has led to an evolution in thinking. ${ }^{9}$ In centers with expertise in both MV repair and robotic surgery, most if not all patients with severe primary MR with appropriate vascular and coronary anatomy may reasonably be considered for early MV repair via robotic approaches regardless of the extent of MV prolapse.

\section{WHO SHOULD UNDERGO ROBOTIC MITRAL VALVE REPAIR?}

\section{Patient Selection and Stratification}

Robotic mitral repair is appropriate for both degenerative and functional MV disease. However, operative risks and mitral anatomy/pathology should be considered when selecting patients for the procedure.

\section{Risk Stratification}

Patients should be screened for comorbid conditions that may preclude the selection of the robotic technique. ${ }^{10}$

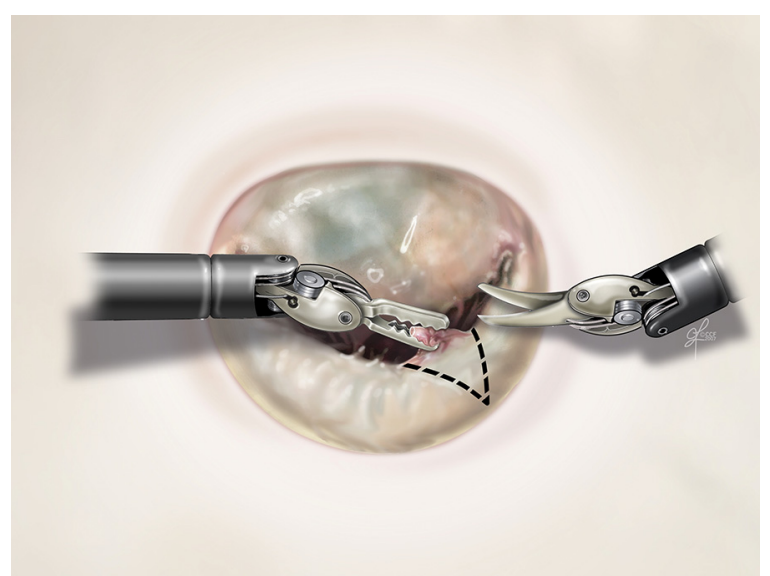

FIGURE 1. Robotic MV repair of middle scallop posterior mitral leaflet prolapse using triangular resection followed by a 2-layer Prolene suture reconstruction

Robotic MV repair generally is done through a right chest approach, and thus, intra-thoracic pathology may be a contraindication. Table 1 demonstrates plausible and relative contraindications for selecting the robotic MV repair approach. Many of the latter can be managed to provide a safe robotic MV repair operation.

\section{Patho-Anatomic Stratification}

Patients who have degenerative MV disease and meet the risk selection criteria can be stratified according to anatomic location, pathology, and robotic MV repair complexity. Surgeons beginning a robotic MV repair program may consider initially selecting patients with posterior leaflet pathology alone. Thereafter, anterior leaflet repair techniques may be added to a surgeon's repair armamentarium. Having gained expertise in repairing anterior and posterior pathology subsets, experienced surgeons may consider advancing selection criteria to incorporate bileaflet prolapse, including Barlow's disease. The latter may require the use of several different techniques during the repair procedure.

The assessment of patients with functional MV disease may require further selection criteria. In this condition, repair technique relates to the degree of annular and ventricular dilatation, papillary muscle displacement, dynamic cardiac function, and degree of leaflet tethering. Patients with localized regional ventricular dysfunction are more amenable to robotic MV repair.

\section{Imaging}

Patients with significant risk factors for carotid/ peripheral vascular disease should be screened by computed tomography (CT)/ultrasound. Patients at risk for coronary artery disease should undergo a cardiac catheterization or CT angiography. A right heart catheterization may be indicated in patients who have significant pulmonary 
TABLE 1. Contraindications for robotic mitral valve repair

$\begin{array}{ll}\begin{array}{c}\text { Contraindications } \\ \text { Previous right thoracotomy } \\ \text { Severe pulmonary dysfunction }\end{array} & \begin{array}{c}\text { Right ventricular dysfunction } \\ \text { Pulmonary hypertension } \\ \text { (fixed }>60 \text { torr) }\end{array} \\ \begin{array}{c}\text { Myocardial infarction or } \\ \text { ischemia }<30 \mathrm{~d}\end{array} & \begin{array}{c}\text { Significant (more than } \\ \text { mild-moderate) aortic } \\ \text { valve insufficiency }\end{array} \\ \begin{array}{c}\text { Coronary artery disease } \\ \text { requiring CABG }\end{array} & \text { Mitral annular calcification } \\ \text { Severe generalized peripheral } & \text { Severe liver dysfunction } \\ \text { vascular disease } & \text { Significant bleeding disorders } \\ \text { Symptomatic cerebrovascular } & \text { Calcification of the aortic root/ } \\ \text { disease or stroke }<30 \mathrm{~d} & \text { ascending aorta } \\ \text { Significant aortic root/ } & \\ \text { ascending aortic dilatation } & \text { Asymptomatic cerebrovascular } \\ \text { Relative contraindications } & \text { disease } \\ \text { Previous sternotomy } & \text { Poor LV function (EF }<50 \%) \\ \text { Moderate pulmonary } & \end{array}$

$C A B G$, Coronary artery bypass grafting; $L V$, left ventricular; $E F$, ejection fraction $P C I$, percutaneous catheter intervention.

hypertension, especially with depressed right ventricular function. Last, patients with sternal or thoracic deformities should be evaluated by CT. In these circumstances, CT data help determine whether robotic instrument trajectories will be compromised.

An excellent transthoracic echocardiography or transesophageal echocardiography study should be performed to determine the operative necessity and plan. In the operating room, transesophageal echocardiography to delineate MV anatomy in detail is essential. ${ }^{11}$

\section{WHAT ARE THE TECHNICAL MANDATES OF ROBOTIC MITRAL VALVE REPAIR?}

Repair of the MV using robotic instrumentation shares some similarities with other right chest approaches using conventional instrumentation, such as nonsternotomy perfusion techniques and exposure of the valvular anatomy from the right lateral chest. Insertion of robotic instruments into the right chest can be performed through a minithoracotomy, ${ }^{12}$ similar to handheld instrument approaches or via a totally endoscopic approach. ${ }^{13}$ The latter has the advantage of transient pressurization of the right pleural space to protect the diaphragm, liver, and mediastinal structures during port insertion.
However, instrumentation of the valvular structures with robotic instruments is uniquely different than with handheld instruments. After inserting the robotic instruments delivered from the instrument cart on the patient's left side, the surgeon leaves the patient's right side and moves to the robotic console. The surgical assistant then moves to the patient's right side and has ready access to the operative field through a small service port or mini-thoracotomy. From the console, the surgeon can perform precise movements inside the left atrium using the mechanical wrists. However, unlike conventional approaches with 2 handheld instruments functioning at the level of the MV, the robotic surgeon has 2 robotic instruments working in conjunction with 2 handheld instruments manipulated by the assistant working through the service port. This relationship creates a unique operative paradigm for MV surgery.

The goal of robotic MV surgery from the inception was exact replication of each proven step of conventional MV repair to attain the known efficacy and durability outcomes that have been proven over the preceding decades. Achieving this goal using the robotic operative platform required the reengineering of surgical tasks. Traditional repairs were deconstructed into a series of surgical steps routinely performed with 2 handheld instruments. Robotic surgeons then determined how these maneuvers could be accomplished using 2 robotic hands working in conjunction with the 2 handheld instruments of the assistant. Tasks requiring 3-dimensional vision and surgical decisionmaking, such as cutting, suturing, and sizing, became the providence of the console surgeon, whereas suctioning, retracting, suture following, and knot tying were more efficiently performed by the assistant. These reengineered tasks were then reconstructed to replicate the traditional repairs. Unique handheld instruments were developed to facilitate this process. As the performance of these hybrid robotic-handheld tasks became more harmonious, perfusion and ischemic times decreased, allowing more complex MV pathologies to be addressed. This same reengineering process was then carried out for adjunctive tasks, such as left atrial appendage closure, ablation for atrial fibrillation, and tricuspid repair. By combining nonsternotomy perfusion techniques and the evolved robotic MV operative paradigm, it is possible to offer robotic surgery to the majority of patients with MV disease. ${ }^{14}$ Furthermore, concomitant Cox-Maze IV procedures using cryoablation or tricuspid valve repair can be performed with relative ease. ${ }^{15,16}$

Operating inside the heart with robotic instruments has 2 notable deficiencies. First, the robotic surgeon has no sense of proprioception. Robotic surgeons must be highly disciplined to avoid moving a robotic instrument unless it is in the endoscopic visual field. Newer model robotic systems have visual aids to allow the surgeon to locate instruments outside the endoscopic field without invoking the help of 
the patient-side assistant. Second, the robotic instruments have no tactile feedback. In practice, this has not been a practical limitation. Advanced radiologic and echocardiographic imaging results in few unexpected findings at the MV. Robotic surgeons also develop an "ocular tactility" similar to that used by professors in the training of younger surgeons.

Robotic MV surgery should be considered a subspecialty of cardiac surgery, perhaps best learned in an apprentice or fellowship setting. Mastering this platform involves several concurrent learning curves, including those of nonsternotomy perfusion, robotic instrument control, the MV operative paradigm, and advanced MV repair techniques. Initiation of a robotic mitral program is facilitated if team members already have proficiency in 1 or more of these areas. ${ }^{17}$ It should be practiced at larger institutions focused on MV disease where dedicated equipment and personnel can be provided. A substantial volume of procedures is necessary to maintain proficiency of the robotic team.

\section{WHAT ARE THE ADVANTAGES OF ROBOTIC MITRAL VALVE REPAIR?}

There are several potential advantages of robotic MV repair versus standard thoracoscopic approaches. First, enhanced surgical dexterity is allowed, facilitating precise movements of instruments in the closed chest milieu and avoiding the fulcrum effect characteristic of long shafted endoscopic instruments experienced during minimally invasive procedures. Second, high-definition 3-dimensional visualization places the surgeon inside the left atrium with the line of vision parallel to the flow of blood into the valve. Visualization of the subvalvular apparatus is superior to that obtained using other approaches, so that any type of myxomatous pathology including fibroelastic deficiency and Barlow's disease can be treated with the standard techniques of triangular resection or insertion of artificial chordae edgeto-edge repair or commissural advancement. Third, the cosmetic results are appreciated by both female and male patients, particularly in patients with prior breast reconstruction and may, in some programs, be smaller using robotic approaches. Finally, because of the reduced surgical trauma and avoidance of the median sternotomy, the requirement of heterologous blood products $(7 \%)$ and the incidence of atrial fibrillation (odds ratio, 0.79) and postoperative pain have been reported to be lower in minimally invasive mitral procedures. ${ }^{18,19}$

\section{WHAT ARE THE PUBLISHED OUTCOMES OF ROBOTIC MITRAL VALVE REPAIR?}

After the first endoscopic MV repair in 1998 using an early prototype of the da Vinci Surgical System (Intuitive Surgical, Inc, Sunnyvale, Calif), a Food and Drug Administration trial involving 20 patients was performed by Chitwood $^{20}$ in 2000 to investigate the safety and efficacy of robotic MV procedures. The short-term results demonstrated that although crossclamp and operative times were longer compared with conventional median sternotomy, there was no significant difference with regard to postoperative morbidity and mortality. Later, a subsequent multicenter follow-up study involving 112 patients reaffirmed the safety and efficacy of this technique with no conversion to median sternotomy, a 30-day mortality of $0.7 \%$, and a 5-year freedom from reoperation of $90 \% .{ }^{12}$

Among 8814 MV repair procedures reported to the Society of Thoracic Surgeon Database in 2013, 1132 (12.84\%) were performed using robotic assistance. More recent series using robotic MV repair have duplicated the previous excellent outcomes. ${ }^{9,14,21,22}$ Murphy and colleagues ${ }^{14}$ recently presented their 8-year single-center experience with MV surgery in 1257 consecutive patients; of these, 1167 patients (93\%) underwent MV repair. ${ }^{14}$ At 6 years follow-up, the overall freedom from recurrent MR $2+$ or greater was $85 \%$, and $3.9 \%$ of patients required reoperation for MV repair failure.

Experienced groups have now reported collectively on several thousand patients who have undergone robotassisted MV repair with a hospital mortality rate of well less than $0.9 \%$, stroke rate of $0.6 \%$ to $1.7 \%$, reexploration for bleeding of $2.2 \%$ to $4.7 \%$, and rare chest wall infections. ${ }^{9,14,16,21-23}$ Furthermore, the incidence of iatrogenic aortic dissection, phrenic nerve palsy, and groin infections have all decreased to approximately $0 \% .{ }^{23}$ In the most recent series reporting results of patients who underwent robotic MV repair, most of whom had ACC/AHA class IIa indications (mean ejection fraction 65\%, New York Heart Association I/II $95 \%$ ), the median crossclamp time for patients undergoing correction of all complexities of leaflet prolapse was 53 minutes. By analyzing follow-up that was $98.8 \%$ complete, overall survival was shown to be $99.5 \%$ at 5 years, and New York Heart Association functional class I/II was documented in $97.9 \%$ of patients. The 5-year freedom from MR recurrence was $94.6 \%$, and 5-year freedom from reoperation was $97.7 \%$. ${ }^{9}$ Robotic repair is a particularly appealing option for patients with stage $\mathrm{C} 1$ chronic degenerative MR to eliminate regurgitation and restore long-term survival. ${ }^{2}$

Several studies have demonstrated that although initial crossclamp, cardiopulmonary bypass, and total operative times were longer as programs began, there were no differences in morbidity and mortality between groups undergoing robotic versus nonrobotic MV repair. ${ }^{3,24}$ Robotic MV repair recently has been shown to be associated with a shorter hospital length of stay and quicker return to work., ${ }^{3,14,24,25}$ Although robotic MV repair was initially associated with higher total hospital resource use, costs have decreased significantly with experience and with the evolution of programmatic efficiencies. The total hospital cost associated with the use of robotic MV repair has now become similar to that for conventional open operation $(\$ 30,606$ vs $\$ 31,310)$, particularly in high-volume centers. ${ }^{6,25}$ 


\section{CONCLUSIONS}

Robotic MV repair is now routinely and safely performed for complete anatomic correction of all categories of MV leaflet prolapse, regardless of complexity. Robotic repair can be undertaken with or without concomitant tricuspid valve repair and atrial fibrillation ablation procedures. ${ }^{3,16}$ Compared with conventional sternotomy, this procedure offers patients the advantages of reduced blood loss, lower risk of incisional infection and atrial fibrillation, shorter hospital length of stay, quicker return to normal activities, and a superior cosmetic result. ${ }^{3,21,24}$ Midterm quality outcomes after robotic mitral repair are excellent, and thus the procedure may be particularly appealing in asymptomatic patients with preserved LV function undergoing correction of severe MR according to $\mathrm{ACC} /$ AHA class IIa Guideline recommendations to optimize long-term survival and decrease late heart failure risk. ${ }^{1,3,9}$

\section{References}

1. Nishimura RA, Otto CM, Bonow RO, Carabello BA, Erwin JP, Guyton RA, et al. 2014 AHA/ACC guideline for the management of patients with valvular heart disease: a report of the American College of Cardiology/American Heart Association Task Force on Practice Guidelines. J Am Coll Cardiol. 2014;63:e57-185.

2. Suri RM, Vanoverschelde J-L, Grigioni F, Schaff HV, Tribouilloy C, Avierinos JF, et al. Association between early surgical intervention vs watchful waiting and outcomes for mitral regurgitation due to flail mitral valve leaflets. JAMA. 2013;310:609-16.

3. Suri RM, Burkhart HM, Daly RC, Dearani JA, Park SJ, Sundt TM, et al. Robotic mitral valve repair for all prolapse subsets using techniques identical to open valvuloplasty: establishing the benchmark against which percutaneous interventions should be judged. J Thorac Cardiovasc Surg. 2011;142:970-9.

4. Chatterjee S, Rankin JS, Gammie JS, Sheng S, O’Brien SM, Brennan JM, et al. Isolated mitral valve surgery risk in 77,836 patients from the Society of Thoracic Surgeons database. Ann Thorac Surg. 2013;96:1587-95.

5. David TE, Armstrong S, McCrindle BW, Manlhiot C. Late outcomes of mitral valve repair for mitral regurgitation due to degenerative disease. Circulation. 2013; 127:1485-92.

6. Suri RM, Thompson JE, Burkhart HM, Huebner M, Borah BJ, Li Z, et al. Improving affordability through innovation in the surgical treatment of mitral valve disease. Mayo Clin Proc. 2013;88:1075-84.

7. Glower DD, Kar S, Trento A, Lim DS, Bajwa T, Quesada R, et al. Percutaneous mitral valve repair for mitral regurgitation in high-risk patients: results of the EVEREST II study. J Am Coll Cardiol. 2014;64:172-81.

8. Yazdchi F, Koch CG, Mihaljevic T, Hachamovitch R, Lowry AM, He J, et al. Increasing disadvantage of "watchful waiting" for repairing degenerative mitral valve disease. Ann Thorac Surg. 2015;99:1992-2000.
9. Suri RM, Taggarse A, Burkhart HM, Daly RC, Mauermann W, Nishimura RA, et al. Robotic mitral valve repair for simple and complex degenerative disease: mid-term clinical and echocardiographic quality outcomes. Circulation. 2015; 132:1961-8.

10. Chitwood WR Jr. Robotic mitral valve repair: techniques and results. In: Chitwood WR Jr, ed. Atlas of Robotic Cardiac Surgery. New York: Springer; 2014:231-59.

11. D’Alonzo C, Gorrin-Rivas M, Mackensen G. Three dimensional transesophageal echocardiographic planning. In: Chitwood WR Jr, ed. Atlas of Robotic Cardiac Surgery. New York: Springer; 2014:33-54.

12. Nifong LW, Chitwood W, Pappas P, Smith CR, Argenziano M, Starnes VA, et al. Robotic mitral valve surgery: a United States multicenter trial. J Thorac Cardiovasc Surg. 2005;129:1395-404.

13. Murphy DA, Miller JS, Langford DA, Snyder AB. Endoscopic robotic mitral valve surgery. J Thorac Cardiovasc Surg. 2006;132:776-81.

14. Murphy DA, Moss E, Binongo J, Miller JS, Macheers SK, Sarin EL, et al. The expanding role of endoscopic robotics in mitral valve surgery: 1257 consecutive procedures. J Thorac Cardiovasc Surg. 2015;100:1675-82.

15. Lewis CT, Stephens RL, Tyndal CM, Cline JL. Concomitant robotic mitral and tricuspid valve repair: technique and early experience. Ann Thorac Surg. 2014; 97:782-7.

16. Nifong LW, Rodriguez E, Chitwood WR. 540 consecutive robotic mitral valve repairs including concomitant atrial fibrillation cryoablation. Ann Thorac Surg. 2012;94:38-43.

17. Yaffee DW, Loulmet DF, Kelly LA, Ward AF, Ursomanno PA, Rabinovich AE, et al. Can the learning curve of totally endoscopic robotic mitral valve repair be short-circuited? Innovations (Phila). 2014;9:43-8.

18. Ryan WH, Brinkman WT, Dewey TM, Mack MJ, Prince SL, Herbert MA. Mitral valve surgery: comparison of outcomes in matched sternotomy and port access groups. J Heart Valve Dis. 2010;19:51-9.

19. Suri RM, Antiel RM, Burkhart HM, Huebner M, Li Z, Eton DT, et al. Quality of life after early mitral valve repair using conventional and robotic approaches. Ann Thorac Surg. 2012;93:761-9.

20. Nifong LW, Chu VF, Bailey BM, Maziarz DM, Sorrell VL, Holbert D, et al. Robotic mitral valve repair: experience with the da Vinci system. Ann Thorac Surg. 2003;75:438-43.

21. Mihaljevic T, Jarrett CM, Gillinov AM, Williams SJ, DeVilliers PA, Stewart WJ, et al. Robotic repair of posterior mitral valve prolapse versus conventional approaches: potential realized. J Thorac Cardiovasc Surg. 2011;141: 72-80. e1-4.

22. Ramzy D, Trento A, Cheng W, De Robertis MA, Mirocha J, Ruzza A, et al. Three hundred robotic-assisted mitral valve repairs: the Cedars-Sinai experience. $J$ Thorac Cardiovasc Surg. 2014;147:228-35.

23. Trento A, Ramzy D, De Robertis M, Mirocha J, Cheng W, Czer L. Ten Years With Robotic Assisted Mitral Valve Repair: One Center's Experience. Florence, Italy: ICCAD; 2015.

24. Paul S, Isaacs AJ, Jalbert J, Osakwe NC, Salemi A, Girardi LN, et al. A population-based analysis of robotic-assisted mitral valve repair. Ann Thorac Surg. 2015;99:1546-53.

25. Mihaljevic T, Koprivanac M, Kelava M, Goodman A, Jarrett C, Williams SJ, et al. Value of robotically assisted surgery for mitral valve disease. JAMA Surg. 2014; 149:679-86. 